\title{
Discurso, Referenciação e Construção de Jdentidades Políticas: - caso do Occupy Wall Street
}

Discourse, Referenciation and Construction of Political Identity: THE CASE OF OCCUPy WaLl STREeT

\section{Thaysa Maria Braide de Moraes Cavalcante* Raimundo Ruberval Ferreira**}

Resumo: O presente artigo objetiva empreender uma análise da construção identitária do Occupy Wall Street (OWS), movimento norte-americano que se opunha à política financeira do capitalismo e, consequentemente, à forte influência exercida pelo capital sobre o Estado. Assim, buscamos responder à questão de como se dá a construção discursiva da identidade desse objeto de discurso, a partir das estratégias referenciais mobilizadas no texto da Declaração de Autonomia, documento aprovado em reunião da Assembleia Geral do movimento. Nosso aporte teórico-metodológico consiste de uma articulação entre a teoria do discurso, do cientista político Ernesto Laclau (1990, 2011; LACLAU; MOUFFE, 2001) - especialmente suas considerações acerca da relação entre discurso, antagonismo e construção de identidades políticas por meio de uma lógica da equivalência -, e os estudos da referenciação, na perspectiva de autores como Apothéloz e Reichler-Béguelin (1995), Koch (2005, 2015), Marcuschi (2007) e Ciulla e Silva (2008). Utilizando

\footnotetext{
* Mestre em Linguística Aplicada pela Universidade Estadual do Ceará (2016). Professora da rede municipal de Fortaleza. Contato: thaysambmcavalcante@gmail.com.

** Doutor em Linguística pelo Instituto de Estudos da Linguagem da Universidade Estadual de Campinas (2005). Professor Adjunto do Curso de Letras e do Programa de Pós-Graduação em Linguística Aplicada da Universidade Estadual do Ceará. Contato: ruber.rubens@gmail.com.
} 
como categoria de análise textual as expressões anafóricas - sem desprezar outros elementos, como alguns dêiticos, que interferem no processo de construção do objeto de discurso em questão - atentaremos para o fato de que essa construção configura o OWS como o que Laclau chama significante vazio, cuja identidade é esculpida através da formação e expansão de uma cadeia de equivalências, que se estabelece a partir de uma relação antagônica. Por fim, discutiremos algumas questões referentes a esse modo de construção identitária, de modo a encarar a linguagem não apenas como forma de materialização das tensões sociais, mas como o lugar privilegiado das lutas sociais acarretadas por essas tensões.

Palavras-chave: Discurso. Referenciação. Identidades políticas.

Abstract: This article aims to undertake an analysis of identity construction of the Occupy Wall Street (OWS), North American movement that opposed the financial policy of capitalism and, consequently, the strong influence of the capital of the State. Thus, we aim to answer the question of how does the discursive construction of identity of this object of discourse, from the referential strategies mobilized in the text of the Statement of Autonomy, document approved by the General Assembly of movement. Our theoretical and methodological support consists of a link between the theory of discourse, the political scientist Ernesto Laclau (1990, 2011; LACLAU; MOUFFE, 2001) - especially his remarks about the relationship between discourse, antagonism and construction of political identities through an equivalence of logic -, and studies of referentiation from the perspective of authors such as Apothéloz e Reichler-Béguelin (1995), Koch (2005, 2015), Marcuschi (2007) e Ciulla e Silva (2008). Using as textual analysis category anaphoric expressions - without neglecting other elements, like some deictics, that interfere in the construction process of the discourse object in question - we attention to the fact that this construction sets the OWS as what Laclau calls empty significant whose identity is carved through the formation and expansion of a chain of equivalence, which is established from an antagonistic relationship. Finally, we discuss some issues concerning this identity construction mode in order to face the language not only as a way of materialization of social tensions but as the privileged place of social struggles brought about by these tensions. Keywords: Discourse. Referenciation. Political identities. 


\section{Introdução}

Embora a relação entre linguagem e mundo aparente seja um assunto cuja discussão se possa descartar, pois o fato de "saber que [quando usamos a linguagem] estamos construindo modos de existência e referenciação e não apenas comunicando fatos ontológicos" (MARCUSCHI, 2007, p. 126) já não é novidade no mundo acadêmico, sua pertinência se faz ver ao percebermos um social contemporâneo marcado por uma gama de tensões sociais, políticas e culturais que se desdobram em expressivas doses de racismo, sexismo, homofobia, fundamentalismos e tantas outras formas de violência que aqui poderíamos arrolar. Subjacente a elas, há um entendimento de verdade ainda fortemente ligado a tentações essencialistas, em que o discurso aparece mais como revelador daquilo que seja a realidade do que propriamente como constitutivo dela. No entanto, tomando como referência algumas abordagens antiessencialistas, a discussão que segue se acerca de dois pressupostos fundamentais: o primeiro é o de que todos os objetos constituem-se como objetos de discurso (MONDADA; DUBOIS, 2003), e o segundo, o de que "toda configuração social é significativa" (LACLAU; MOUFFE, 2001, p. 100, tradução nossa, grifos do original $)^{1}$.

Tomando como ponto de partida esses dois pressupostos, este artigo tem por objetivo analisar a construção identitária do movimento Occupy Wall Street (OWS), um movimento social rizomático ${ }^{2}$, de base anarquista, que emergiu no cenário norte-americano, em 17 de setembro de 2011, quando da ocupação do parque Zuccotti, em Manhattan, coração financeiro dos EUA - à semelhança de (e influenciado por) movimentos como a Primavera Árabe e os Indignados Espanhóis, guardadas as particularidades de cada um. Protestavam, precipuamente, contra a política financeira capitalista responsável por um cenário de concentração de grande parte da renda e do riqueza

${ }^{1}$ Cf. LACLAU, E. New Reflections on the Revolution of Our Time. Londres: Routledge, $1990 \mathrm{~b}$.

${ }^{2}$ O termo rizomático foi utilizado por Castells (2013) - "revolução rizomática" -, para denominar um tipo de revolução que possui uma formação tal como a de um rizoma, enfatizando seu caráter horizontal, sem um núcleo ou raiz bem definida, que toma contornos difíceis de delimitar, e que está interligado em todas as suas partes. 
mundial nas mãos de uma parcela mínima da população, enquanto outra, bem mais numerosa, vê seu poder de participação política progressivamente restringido pela lógica do capital e seus aparatos jurídico, legislativo, midiático, além das forças repressoras do Estado.

Dessa forma, buscamos responder à questão de como se dá a construção discursiva da identidade do objeto de discurso Occupy Wall Street, e o faremos buscando as estratégias referenciais que foram mobilizadas no texto da Declaração de Autonomia ${ }^{3}$, documento aprovado em reunião da Assembleia Geral do movimento e publicado em site oficial ${ }^{4}$.

Tomaremos como referencial teórico-metodológico a teoria do discurso, de Ernesto Laclau (1990, 2011; LACLAU; MOUFFE, 2001) especialmente suas considerações acerca da relação entre discurso, antagonismo e construção de identidades políticas por meio de uma lógica da equivalência -, e os estudos da referenciação, na perspectiva de autores como Apothéloz e Reichler-Béguelin (1995), Koch (2005, 2015), Marcuschi (2007) e Ciulla e Silva (2008). Julgamos bastante fecunda a articulação entre essas teorias para analisar a construção de identidades políticas por considerar que tais discussões contêm pressupostos que podem nos ajudar a pensar a linguagem não apenas como forma de materialização das tensões sociais, mas sobretudo como a primeira instância onde as lutas e embates decorrentes dessas tensões acontecem, conforme veremos adiante, quando pensaremos a linguagem em função de sua dimensão constitutiva do que habitualmente chamamos de realidade.

Importa esclarecer que, diante das ponderações teóricas que norteiam esta discussão, a objetividade requerida pela ciência encontra-se, aqui, para somar-se à voz de Maturana (2001, p. 34), posta entre parênteses. Assumimos, portanto, que este é um caminho epistemológico, entre outros possíveis, para se chegar à compreensão/construção do objeto em questão, dadas as escolhas empreendidas em todo o processo da pesquisa, escolhas tais que devem ser vistas em função de preocupações e implicações ético-políticas.

\footnotetext{
${ }^{3}$ Considerando as dimensões exigidas para este trabalho, optamos aqui por apresentar a análise de apenas alguns trechos do texto.

${ }^{4}$ Disponível em: < http://bit.do/cURNf $>$.
} 


\section{Sobre a Instabilidade das Categorias do Mundo e a Construção de Objetos de Discurso}

Afirmamos anteriormente que todo objeto deve ser visto como um objeto de discurso, ou seja, o mundo é construído no curso das práticas dos sujeitos, que o torna relativamente estável pelas categorias (ou identidades) que constrói e que são naturalizadas (MONDADA; DUBOIS, 2003, p. 20). No entanto, vale lembrar que é preciso ter um certo cuidado com essa afirmação, pois ela não quer dizer, em absoluto, que estamos aqui incorrendo em um idealismo ingênuo.

Considerar que “a 'verdade', factual ou outra, sobre o ser dos objetos é constituída num contexto teórico e discursivo" , conforme afirmam Laclau e Mouffe (2001, p. 105), não significa eliminar das coisas sua existência física independente da linguagem. Devemos ter o cuidado de não fazer confusão entre o ser dos objetos, que, para os autores, é histórico e mutável, e o ente, que não o é. Laclau e Mouffe (2001, p. 101) destacam o exemplo do diamante. Segundo os autores, um diamante é o mesmo objeto físico se estiver no mercado de joias ou no fundo de uma mina. Ele existe enquanto ens (objeto de existência), independente do nosso conhecimento sobre ele; porém sua identidade (ou esse - o seu ser) de mercadoria, por exemplo, só pode ser assumida no interior de uma totalidade discursiva $a^{6}$ (um modo de produção capitalista, como é o nosso caso). Vale lembrar, no entanto, que, mesmo que façamos a distinção entre a existência do objeto e sua significação, não há como abstrair esta daquele, sendo impossível pensar qualquer coisa se não for do interior de um conjunto de significados relativamente estabilizados com os quais mantém relação.

O fato de uma madeira, por exemplo, ser "parte de um produto manufaturado", ou “objeto de contemplação" etc., são identidades construídas por nós para categorizá-la e atribuir-lhe um sentido. Não é recente a discussão de que o ser em si não constitui o a priori da linguagem, resultando

\footnotetext{
5 "the 'truth', factual or otherwise, about the being of objects is constituted within a theoretical and discursive context...".

${ }^{6}$ Por totalidade discursiva, entenda-se discurso em seu sentido mais amplo, conforme será aduzido mais adiante.
} 
tão somente de um efeito dela. A identificação das coisas não consiste, portanto, na ação de rotular "corretamente" o mundo, mas em construí-lo discursivamente, de modo intersubjetivo, e nas lutas pela estabilização de tais construções.

Neste momento, é importante esclarecer o que estamos chamando de discurso. Consideramos duas acepções para o termo. A primeira diz respeito à sua realização mais particular, como discurso religioso, discurso médico etc. A segunda, um pouco mais ampla, toma-o como resultado de uma prática articulatória, ou seja, "toda prática que estabelece uma relação tal entre elementos, que a identidade destes termina por modificar-se como resultado dessa prática"7 (LACLAU; MOUFFE, 2001, p. 105). Para os autores, os elementos correspondem a toda diferença que será articulada. Quando isso ocorre, esses elementos tornam-se momentos (identidades) em relação à prática que os articulou. O ponto articular de amarração dessas diferenças, responsável pela fixidez relativa dos momentos, é chamado ponto nodal. O resultado disso é o que se compreende aqui por discurso. O exemplo a seguir ilustra bem a noção de prática articulatória.

Um país que passa por um governo autoritário que, ao longo do tempo, é visto como corrupto, não acolhedor de demandas de variados setores da sociedade, além de, evidentemente, não-democrático, passa a sofrer uma série de resistências dos mais variados grupos sociais. Desta forma, num primeiro momento, trabalhadores dos mais variados setores laborais, estudantes, grupos sociais os mais diversos (sic) veem que suas demandas particulares não têm sido acolhidas por este governo inepto. Isoladamente, esses diversos grupos sociais demandam suas questões específicas e sentem-se frustrados pela não acolhida das mesmas, quando não o são ainda brutalmente sufocados pelo aparelho repressor do Estado. Nesse momento inicial, segundo a perspectiva da teoria do discurso, estes grupos são vistos como elementos [...]. São elementos, uma vez que não mantêm qualquer relação a priori entre si, mas tão-somente com o frustrante governo

7 "any practice establishing a relation among elements such that their identity is modified as a result of the articulatory practice". 
autoritário. Num determinado instante - a partir de um discurso comum articulador de todas essas diferenças (ponto nodal), como por exemplo, a demanda comum por democracia no contexto daquele Estado - esses grupos se articulam e passam a ser momentos [...] de uma articulação discursiva que tem, como corte antagônico, o regime autoritário (MENDONÇA, 2009, p. 157-158).

Considerar que os objetos do mundo se constituem como objetos de discurso nos leva, portanto, a encarar a referência sob uma perspectiva construtivista (APOTHÉLOZ; REICHER-BÉGUELIN, 1995), o que não implica, necessariamente, desconsiderar a dimensão psíquica do sujeito. Assim, o referente é aqui compreendido como o ponto de estabilização hegemonizado, a ordem simbólica (com suas práticas, instituições e relações sociais) aberta e apenas relativamente estabilizada, sempre em movimento. O referente pode ser visto ainda como uma produção cognitivo-discursiva relativamente estável, gerada intersubjetivamente na prática social, tendo em vista o fato de que a produção discursiva do mundo e das relações sociais se dá sempre em função de um contexto de ação (LACLAU, 1990, p. 102).

Por essa razão, vemos a questão da referenciação como de extrema importância para analisar o modo como a ordem social e as identidades sociais são (re)categorizadas individual ou coletivamente, para daí delinear as possíveis implicações que estas estabelecem em uma dada ordem social, ou seja, como elas participam do fluxo da luta hegemônica, na tentativa de superar e transformar as categorias negativamente marcadas, como categorias estigmatizadas, inferiorizadas. O que tentaremos fazer neste artigo é analisar o modo como a identidade do movimento Occupy Wall Street é construída a partir da análise da Declaração de Autonomia (Statement of Autonomy), da qual apresentamos alguns trechos adiante.

Há uma multiplicidade de quadros teóricos disponíveis acerca da referenciação que coloca, de um lado, as abordagens mais cognitivistas e, de outro, as interacionistas. A perspectiva aqui adotada aproxima-se mais destas últimas, pois se centra muito mais "no que é publicamente manifestado pelos participantes [...] que em processos mentais internos aos sujeitos" $(\mathrm{KOCH}$, 2005 , p. 12), embora não desconsidere que haja processos cognitivos na construção da referência e no modo de interpretá-la. 
Embora, no desenvolvimento das pesquisas em referenciação, várias tentativas taxonômicas tenham surgido, objetivando dar conta da análise da materialidade textual, o que se observa é que elas falham na tentativa de cerrar o fenômeno em categorias analíticas totalizantes. Isso se deve não a uma insuficiência teórico-metodológica, mas à própria complexidade do processo de construção do sentido, que não permite ser encerrado em classificações herméticas. Por seu caráter não linear e por mobilizar uma série de aspectos de natureza não apenas estritamente linguística, mas também sociocognitiva, a referenciação escapa a qualquer tentativa de fechamento e aplicação de categorias previamente estipuladas, o que não significa que não podemos formular categorias analíticas para pensar esses processos. A questão está muito mais ligada ao modo como encaramos o texto na análise, e como consideramos a atuação de fenômenos como anáforas e dêixis, por exemplo: de modo mais aberto, considerando o comportamento e função das expressões em uso para a construção do sentido, ou de modo mais hermético, o que limitaria a análise de algumas construções textuais.

Optamos aqui por um tratamento mais distendido dos processos referenciais, que nos permitirá observar como o referente Occupy Wall Street é construído no texto. Cada forma de retomada, remissão ou referenciação empreendida, tanto a partir de elementos do cotexto quanto dos elementos inferidos com base em uma cognição social compartilhada pelos membros de uma determinada cultura ou grupo social (VAN DIJK, 2008) acrescenta novas informações ao referente, recategorizando-o, permitindo que se construa uma cadeia referencial em que esses elementos são postos em equivalência, diferenciando-se, ao mesmo tempo, de seu outro, (re)articulando-se na mente do leitor de modo a compor uma identidade. Por isso a escolha em analisar as cadeias de equivalência que constroem identidades políticas, de que fala Laclau (2011), através da referenciação: elas nos apontam para o modo complexo de construção de objetos de discurso, constituindo um suporte de análise linguística, através de suas formulações e categorias, sem desconsiderar a dimensão sociopolítica que perpassa todo o processo. 


\section{Discurso, Antagonismo e Construção de Identidades Políticas}

A teoria do discurso de Ernesto Laclau, desenvolvida em parceria com Chantal Mouffe, em 1985, é uma teoria indiscutivelmente política. Nessa proposta de análise, o componente político tem lugar privilegiado. Os autores consideram que a dimensão do "político" constitui-se a partir de relações de poder medidas antagonicamente. Um dos pontos interessantes dessa abordagem é a separação que Mouffe faz entre a política e o político. Enquanto a autora pensa o "político" como um espaço de poder, conflito e antagonismo, isto é, como a própria dimensão do antagonismo, dimensão esta responsável pela constituição das sociedades humanas", a política é concebida como "uma série de práticas e instituições através das quais uma ordem é criada, organizando a coexistência humana no contexto de conflitualidade provido pelo político" (MOUFFE, 2005, p. 9).

Laclau e Mouffe, em sua teoria do discurso, partem do pressuposto psicanalítico de que as relações sociais têm um caráter simbólico, o que significa dizer que elas são constituídas na linguagem ou, em outras palavras, que as relações sociais são sobredeterminadas, isto é, que elas carecem de uma literalidade última que as reduziria, por sua vez, a momentos necessários de uma lei imanente. A implicação mais imediata desse pressuposto é a impossibilidade de fixação de um sentido literal último (LACLAU; MOUFFE, 2001). Isso faz com que a sociedade seja vista como uma organização sempre aberta, uma totalidade impossível, que não existe senão a partir de práticas articulatórias, que "estabelecem relações entre elementos, cujas identidades modificam-se como resultado dessas práticas”. À totalidade dessas práticas, os autores chamam discurso (LACLAU; MOUFFE, 2001).

Em sua primeira formulação teórica, Laclau confere centralidade ao conceito de antagonismo, por ele definido como o limite de toda objetividade, como a impossibilidade de uma determinada identidade constituir-se plenamente pela simples presença do outro antagônico. No entanto, o conceito de antagonismo perde sua centralidade em New reflections on the revolution of our time, de 1990, doravante NR, quando a teoria do discurso de Laclau sofre algumas reformulações. O conceito de antagonismo perde sua centralidade, após crítica do filósofo e psicanalista Slavoj Zizek. Se, antes, antagonismo era entendido como o limite de sentido que o sistema discursivo poderia alcançar tendo em vista a presença do seu corte antagônico, a partir 
dessa nova obra a categoria perde essa dimensão. Laclau admite que o antagonismo não pode ser o limite da objetividade, pois a própria condição do outro antagônico já infere um tipo de simbolização ou inscrição discursiva na estrutura da ordem simbólica. Em NR, antagonismo aparece como parte de um sistema de significação, como condição de identificação. Nesta obra, Laclau volta sua atenção para outra categoria: a de "deslocamento", pensada em um nível anterior ao do "antagonismo".

O antagonismo passa a ser visto, então, como parte de um sistema de significação, e emerge a partir da percepção de uma ameaça, que dá início à produção de um processo articulatório de elementos e, consequentemente, um discurso (MENDONÇA, 2012). As identidades antagônicas e seu discurso são formados por práticas articulatórias que constroem cadeias de equivalência em meio a diferenças. Na luta política, são estabelecidas fronteiras entre um nós e um eles, articulando um conjunto de identidades (momentos) diferenciais em uma mesma cadeia equivalencial, em que uma dessas diferenças (identidade diferencial) assume uma posição hegemônica no interior daquele discurso, e tenta articular a ela outras diferenças, de modo a formar um todo coerente. A presença do opressor, no entanto, é parte da identidade daquele que está lutando contra a opressão, sendo precárias e incompletas as fronteiras que constituem uma divisão social.

Em uma sociedade mais complexa, grupos dominantes e dominados ganham conteúdos os mais diversos, ou seja, as diferenças se expandem e, ao mesmo tempo, "se anulam na medida em que são usadas para expressar algo idêntico que subjaz a todas elas"» (LACLAU; MOUFFE, 2001, p. 127), o ponto em comum entre as diferenças que separam o nós do eles. É o que faz o OWS. Apesar da multiplicidade de diferenças articuladas existentes no movimento (movimento LGBTT, feministas, negros etc.), uma delas é hegemonizada (a condição de afetados pelo capitalismo, ou seja, a dimensão econômica é sobredeterminada às outras), e tenta manter todas as outras diferenças em torno dessa, supostamente comum - o ponto nodal que garantirá (provisoriamente) a unidade do grupo e, ao mesmo tempo, a diferenciação com relação ao seu outro.

\footnotetext{
8 "the differences cancel one other out insofar as they are used to express something identical underlying them all".
} 
A desigualdade entre posições de sujeito presente no social torna possível que uma diferença seja hegemonizada no interior de um determinado grupo, posto que nem toda posição social é "igualmente capaz de transformar seus conteúdos próprios num ponto nodal que possa se tornar um significante vazio" (LACLAU, 2011, p. 76 - grifos nossos), segundo o autor, tão necessário à luta política. Quando uma diferença se apresenta como realizadora de demandas mais extensas, ou seja, quando ela consegue expandir a cadeia de equivalência a um determinado ponto, há grandes chances de que essa particularidade passe a ser o significante de uma completude, encarnando, em momentos particulares, uma luta universal - transformação da sociedade, emancipação etc. Essa operação é o que aqui temos chamado hegemonia. É na luta hegemônica, nessa busca por uma totalidade fechada, que universalidade e particularidade constituem-se mutuamente, fazendo com que uma classe/ grupo torne-se uma hegemonia à medida que consiga êxito em sua tentativa de se apresentar como realizadora/realizador de objetivos mais extensos. Devemos atinar aqui para o fato de que uma total equivalência entre as diferenças, sonho de todo projeto totalitário, é algo impossível, dada a tensão inerente à pluralidade do social com seus valores e interesses por vezes antagônicos. A hegemonia não absorve todas as lutas, ela precisa traçar limites (excluir diferenças) para construir um sistema de significação. No entanto, deve buscar estender ao máximo a cadeia equivalencial que a compõe, e identificá-la com o projeto de mudança, e isso se mostra possível graças à presença de significantes vazios, que, no sentido estrito do termo, é conceituado como um significante sem significado, o que parece quase impossível de ser pensado; ele existe, no entanto, apenas como subversão do signo. É subvertendo o signo que, mesmo não estando ligado a nenhum conteúdo particular, esse significante faz parte de um sistema de significação. Para Laclau (2011, p. 68), não se trata de excesso ou deficiência de significações, mas da "possibilidade teórica de algo que aponte, do interior do processo de significação, a presença discursiva de seus próprios limites”. Assim,

Cada significante constitui um signo mediante sua ligação com um significado particular, inscrevendo-se ele mesmo como uma diferença no interior do processo de significação. [...] Como, no entanto, todos os meios de representação são por sua natureza diferenciais, somente 
se o caráter diferencial das unidades significativas for subvertido, se os significantes se esvaziarem de todo vínculo com significados particulares e assumirem o papel de representar o puro ser do sistema - ou melhor dizendo, o sistema como puro Ser -, tal significado será possível (LACLAU, 2011, p. 71).

O significante vazio é, portanto, um significante do puro cancelamento das diferenças, compondo uma identidade de grupo aparentemente coesa.

\section{A Construção Discursivo-Identitária do $O W S$ : processos de referenciação na Declaração de Autonomia}

As categorias pertinentes à referenciação utilizadas para a análise foram, principalmente, as anáforas, através de expressões anafóricas - nominais (definidas e indefinidas) e predicativas ${ }^{9}$, sem desprezar quaisquer outras marcas linguísticas que contribuam para a construção referencial do objeto de discurso em questão (ou de outro(s) que ajuda(m) a construí-lo). A partir das pistas linguísticas que identificarmos, indicando o(s) tipo(s) de equivalência(s) construído(s), chegaremos a um modo de compreensão da formação identitária do movimento.

O primeiro trecho ${ }^{10}$ apresentado inicia o texto em questão ${ }^{11}$ :

${ }^{9}$ Consideramos, em consonância com Custódio Filho (2011), expressões predicativas, e outros tipos de expressões linguísticas não consideradas por abordagens mais ortodoxas, como expressões referenciais, dado que também contribuem para a construção de objetos-de-discurso. $\mathrm{Na}$ verdade, o estudo da referenciação deve estabelecer um ir e vir constante entre os elementos imediatos dos sistemas da língua e os elementos mais amplos do contexto (cf. Beaugrande, 1997; Hanks, 2008).

${ }^{10}$ Todas as traduções dos textos do OWS são de nossa autoria.

11 “STATEMENT OF AUTONOMY / Occupy Wall Street is a people's movement. It is party-less, leaderless, by the people and for the people. It is not a business, a political party, an advertising campaign or a brand. It is not for sale./ We welcome all, who, in good faith, petition for a redress of grievances through non-violence. We provide a forum for peaceful assembly of individuals to engage in participatory democracy. We welcome dissent. Any statement or declaration not released through the General Assembly and made public online at www.nycga.net should be considered independent of Occupy Wall Street." 


\section{DECLARAÇÃO DE AUTONOMIA}

Occupy Wall Street é um movimento do povo. É sem partido, sem liderança, pelo povo e para o povo. Não é um negócio, um partido político, uma campanha publicitária ou uma marca. Não está à venda.

Nós acolhemos todos que, de boa fé, suplicam por uma reparação das injustiças sem a prática da violência. Promovemos um fórum de reunião pacífica de indivíduos para se envolverem na democracia participativa. Nós acolhemos a dissidência.

Qualquer afirmação ou declaração não lançada pela Assembleia Geral e tornada pública online em www.nycga.net deve ser considerada independente do Occupy Wall Street.

O referente OWS é introduzido ${ }^{12}$ por meio da forma como fora nomeado pelos próprios ativistas do movimento, em outros textos, e pela qual é conhecido. É importante percebermos, aqui, a ausência de um determinante antes de Occupy Wall Street, o que pode criar um efeito de generalização, com um certo afastamento do enunciador com o que diz, em que se percebe que o intuito é dar uma definição do que seja o movimento de modo a parecer verdadeira. Podemos dizer que há uma remissão indireta feita a ele por meio do pronome Nós (inclusive nos casos em que a pessoa é apenas inferível do verbo). Essa remissão se dá mais por uma operação cognitiva de associação (equivalência) entre o locutor e o Occupy Wall Street, razão pela qual o tomamos como um dêitico com função anafórica ${ }^{13}$. Esse tipo de classificação se deve ao fato de que dêixis e anáfora podem tomar caminhos confluentes, sobrepondo-se em termos de funções. No caso em questão, o enunciador torna-se parte daquilo que tenta construir como grupo, instaurando-se como o centro dêitico do enunciado, o que deixa sua subjetividade mais saliente. Isso acontece no momento em que esse enunciador

\footnotetext{
${ }^{12}$ Entenda-se neste artigo introdução como a primeira vez em que o referente aparece no universo discursivo que está sendo criado numa materialidade textual.

${ }^{13}$ Cf. Ciulla e Silva (2008) para uma discussão mais acurada sobre o fenômeno.
} 
tratará das ações empreendidas pelo grupo, e não mais de definições (no sentido estrito do termo). Assim, ele está engajado, é parte de um grupo e está autorizado legitimamente a falar das atividades deste com conhecimento e propriedade. Ao mesmo tempo em que isso acontece, realiza-se a função anafórica, por meio de anáfora indireta, cuja forma pronominal possui dependência interpretativa em relação a algumas expressões precedentes no cotex to (como Occupy Wall Street), introduzindo um novo referente e mantendo a continuidade referencial global (MARCUSCHI, 2005), nos direcionando à crença de que o grupo ao qual corresponde esse Nós é o próprio OWS.

Temos ainda, logo no início, uma expressão predicativa que acrescenta informações para a construção do objeto de discurso OWS; trata-se de um movimento do povo, que estabelece uma identidade de movimento popular ao OWS, identificando-o diretamente, por meio da expressão restritiva, a esse povo, visto também que é por ele e para ele. Além disso, esse povo que caracteriza o movimento é identificado ao novo referente introduzido mais adiante "todos que, de boa fé, suplicam por uma reparação das injustiças sem a prática da violência". Essa associação ocorre não apenas por uma relação direta estritamente linguística, mas por meio da ativação de um conhecimento compartilhado em nossa sociedade. A expressão o povo funciona como uma âncora para esse novo referente. Trata-se do povo como plebs (plebe), não como populus, por isso está identificado à condição de vítima, de povo-massa que é chamado a ter voz através do movimento. No discurso do OWS, atribui-se ao povo valores como justiça e bondade, e rechaça-se a injustiça e a violência. Dessa forma, mais elementos são agregados à cadeia equivalencial para somar-se à faceta identitária do $O W S$, as quais restringem, emprestam unicidade ao referente, isto é, contribuem para torná-lo "mais único", mais diferenciado dos outros. Podemos então dizer que, a cada nova informação, uma recategorização do objeto de discurso é efetuada. A noção de povo, que até então poderia ser vista como abrangente (populus), adquire uma nova identidade, um sentido mais específico e providencial para o efeito de sentido requerido pelo jogo argumentativo que se estabelece no texto.

Na sequência, percebe-se uma movimentação entre particularidade e universalidade, quando é estabelecida uma relação, via anáfora indireta, entre todos que... (e, indiretamente, um movimento do povo) e indivíduos, no segundo 
parágrafo. Os grupos menores ${ }^{14}$ que constituem o movimento são tratados por indivíduos, obscurecendo a identificação de pessoas a determinados grupos sociais. Desse modo, tem-se uma ênfase dada à particularidade e à autonomia, como se cada indivíduo fosse destituído de qualquer identidade social e tivesse a liberdade de não pertencer a grupo algum. Assim fica mais fácil fazer parecer que, na passagem da particularidade do indivíduo (grupos menores) à universalidade do grupo (Occupy), tendo sido estabelecida a equivalência de valores e interesses, não há tensões: a individualidade, diferença que é, pode, à medida que se identifica com os valores do grupo, passar, sem maiores problemas, a fazer parte dele. Esse grupo estabelece relação de equivalência, a partir de tudo o que fora exposto até então, com o povo; por isso, caracteriza-se como movimento popular, sendo aquilo que não faz parte dessa categoria o que chamaremos especificamente neste artigo de "nãopovo" (que, numa perspectiva mais abrangente, a partir da leitura de outros textos relacionados à temática, pode ser identificado como 0 1\%).

Outro fato para o qual é importante chamar a atenção diz respeito à introdução do referente democracia participativa e tudo o que se encontra no seu entorno cotextual mais próximo, que nos leva a tecer considerações sobre o OWS. Fazer com que pessoas se envolvam em um ato democrático pressupõe um sujeito que realiza essa ação, e este só pode ser localizado, neste caso, por meio de inferência, estabelecendo uma relação com o Nós, inferível a partir da desinência verbal de promovemos. Isso atribui ao movimento OWS o papel temático de agente, com a finalidade de, no caso do uso da expressão para se envolverem, alcançar a meta, no caso, uma participação democrática direta dos indivíduos. Por essa razão, podemos afirmar uma relação indireta de equivalência entre democracia e Occupy Wall Street.

Muito interessante, ainda, é notar, nesse trecho, o modo como o OWS constrói predicações a partir de negações. Quando fala daquilo que não é, deixa mais explícitos os limites de seu ser (como aqui compreendemos essa categoria), sua identidade, construindo, ao mesmo tempo, a identidade de

\footnotetext{
${ }^{14}$ Consideramos grupos menores apenas em oposição ao grupo maior que é o Occupy, o qual abriga todos eles. Além disso, quando falamos em grupo, não necessariamente estamos considerando um grupo institucional, mas grupos sociais de forma mais ampla, como o grupo dos desempregados, dos idosos, dos estudantes etc.
} 
seu corte antagônico. Assim, temos que um negócio (âmbito do mercado e do consumo) um partido político (âmbito das instituições sociais já cristalizadas) uma campanha publicitária e uma marca (ambas também no âmbito do mercado e do consumo), expressões nominais indefinidas, dizem respeito a tudo o que o OWS não é, ou seja, tudo aquilo que, ao ser excluído de seu interior, estabelece os limites que o circunscrevem. Esses elementos diferenciais excluídos, sequencialmente mencionados, se equivalem, desse modo, na identidade daquilo que não é o $O W S$, ou seja, do não-povo, os quais também são identificados com os elementos partido e liderança, ausentes no movimento. Tudo isso acrescenta informações importantes para a construção de uma identidade subversiva para esse grupo, à medida que busca romper com a ideia predominante de que toda agremiação política possui líderes ou pode ser identificada a um partido.

Há, no final do segundo parágrafo, a afirmação de uma atitude que pode ser vista como democrática, e que caracteriza o OWS: o nós que constitui o grupo acolhe a dissidência. Percebemos a expressão a dissidência, o referente instaurado por meio de uma expressão definida, como estabelecendo uma relação meronímica com os indivíduos, citados na oração imediatamente anterior. Isso se dá pelo fato de que a ideia de indivíduos reunidos e envolvidos numa democracia pressupõe a existência de posicionamentos diferentes entre eles, e isso também se dá em um âmbito cognitivo, de conhecimento compartilhado em uma determinada cultura. Há, no entanto, uma opacidade muito grande do verbo acolher, pois, em momento algum o enunciador dá indícios de como essa dissidência é tratada, silenciando (ou velando) as tensões inerentes à reunião de posições divergentes em um mesmo grupo.

No terceiro parágrafo, temos a expressão definida “(pel) a Assembleia Geral', que aparece sob a forma do já dado. Podemos dizer que ela remete indiretamente ao movimento por ser uma parte da ação que este realiza, configurando-se, segundo classificação proposta por Marcuschi (2005), como uma anáfora indireta baseada em inferências que se ancoram no universo textual. A assembleia é a reunião dos grupos que compõem o OWS para, entre outras coisas, a tomada de decisões concernentes aos direcionamentos de suas ações. Em seguida, novamente, temos a retomada total, correferencial, de Occupy Wall Street, mais uma vez de modo a separar o sujeito que enuncia do objeto, criando o efeito de objetividade e colocando o Occupy como instância superior àquele. 
Seguindo à análise, $\operatorname{temos}^{15}$ :

Nós gostaríamos de esclarecer que o Occupy Wall Street não é e nunca foi afiliado a nenhum partido político estabelecido, candidato ou organização. Nossa única afiliação é com o povo.

O povo que está trabalhando junto para criar esse movimento são seus parceiros únicos e mútuos. Se você escolheu empregar recursos para a construção desse movimento, principalmente seu tempo e trabalho, então ele também é seu.

Qualquer organização é bem vinda a nos ajudar, com o conhecimento de que isso vai implicar um questionamento de seus próprios quadros institucionais de trabalho e hierarquia e a integração de nossos princípios em seus modos de ação.

Mais uma vez, percebemos a equivalência estabelecida entre Occupy e povo, de modo que, por oposição, partido político estabelecido, candidato e organiżação, tendo sido excluídos da relação equivalencial com o movimento, não deixam de equivaler-se com aquilo a que ele (o movimento) se opõe - o seu outro. A expressão definida esse movimento sugere mais uma vez a ideia de grupo organizado que luta em favor de uma causa. Percebamos a atmosfera de cooperação que se cria em torno do movimento: o trabalho entre os membros (indivíduos recategorizados como parceiros) é conjunto, e todos aqueles que se propõem a fazê-lo são, individualmente (mais uma vez a ideia de autonomia é evocada) e mutuamente (o que sugere cooperação) seus parceiros. As escolhas lexicais aqui empreendidas também contribuem para a

\footnotetext{
15 "We wish to clarify that Occupy Wall Street is not and never has been affiliated with any established political party, candidate or organization. Our only affiliation is with the people./ The people who are working together to create this movement are its sole and mutual caretakers. If you have chosen to devote resources to building this movement, especially your time and labor, then it is yours./ Any organization is welcome to support us with the knowledge that doing so will mean questioning your own institutional frameworks of work and hierarchy and integrating our principles into your modes of action."
} 
progressão do referente analisado, introduzindo novos referentes que, ao associarem-se a ele, colaboram para a construção de uma cadeia referencial que reforça a identificação do grupo a uma maioria social denominada povo, aos valores de autonomia, solidariedade, cooperação e união, tidos como desejáveis, e a processos materiais e relacionais identificativos (HALLIDAY, 1994), que o estabelecem, respectivamente, como agente e como identificado desses processos, consistindo em um esforço de identificação como um grupo de comportamento eminentemente ativo. Todos esses elementos diferenciais são postos, dessa forma, em equivalência, de modo que tudo (ou, como no texto, qualquer organiz̧ação) o que cognitivamente puder ser associado a esses valores e ações fará parte daquilo que se denomina Occupy Wall Street, criando, assim, sua identidade de grupo. O que caracteriza ainda o grupo é a atitude questionadora e subversiva com relação a um modo já existente, predominante, hegemônico, de organização das instituições. Percebemos isso pelo fato de que não seria exatamente qualquer organiz̧ação que poderia fazer parte do grupo, mas apenas aquelas que se dispusessem a assumir a mesma postura questionadora e os mesmos valores ali compartilhados, o que implica a negação da diferença em favor da equivalência, pois há diferenças que não são compatíveis com o grupo. Uma postura diferente da requerida faria parte do outro lado da fronteira identitária, constituindo, no limite, a própria fronteira em si.

Para finalizar nossa análise, tomemos o último trecho do texto ${ }^{16}$.

16 “SPEAK WITH US, NOT FOR US. Occupy Wall Street values collective resources, dignity, integrity and autonomy above money. We have not made endorsements. All donations are accepted anonymously and are transparently allocated via consensus by the General Assembly or the Operational Spokes Council./We acknowledge the existence of professional activists who work to make our world a better place. If you are representing, or being compensated by an independent source while participating in our process, please disclose your affiliation at the outset. Those seeking to capitalize on this movement or undermine it by appropriating its message or symbols are not a part of Occupy Wall Street./We stand in solidarity. We are Occupy Wall Street”. 


\section{FALE CONOSCO, NÃO PARA NÓS}

O Occupy Wall Street valoriza as gestões coletivas, a dignidade, a integridade e a autonomia acima do dinheiro. Nós não fizemos autenticações. Todas as doações são aceitas anonimamente e são distribuídas com transparência através de um consenso da Assembleia Geral ou do Conselho Operacional de Porta-Vozes ${ }^{[17]}$.

Nós reconhecemos a existência de ativistas profissionais que trabalham para fazer do nosso mundo um lugar melhor. Se você está representando ou sendo compensado por uma fonte independente durante sua participação no nosso processo, por favor, divulgue sua afiliação no início. Aqueles que procuram capitalizar esse movimento ou enfraquecê-lo apropriando-se de sua mensagem ou símbolo, não fazem parte do Occupy Wall Street.

Solidarizamo-nos. Somos Occupy Wall Street.

Aqui, percebemos novamente a presença e o afastamento do enunciador com relação ao Occupy, colocando-se, e a seus pares, no texto (nós), e dele retirando-se (O Occupy Wall Street), jogando com os efeitos de subjetividade e objetividade. Os termos a Assembleia Geral e o Conselho Operacional de Porta-Vozes, novamente interpretados como anáforas indiretas baseadas em inferências que se ancoram no universo textual, garantem uma caracterização do Occupy como movimento democrático organizado, que provê formas bem estruturadas de participação popular.

Mais um elemento é acrescido à rede de equivalências estabelecida pelo Occupy, quando da introdução de um novo referente: ativistas profissionais, cuja existência [no interior do movimento] é reconhecida. Além disso, podemos afirmar, a partir da relação inferida entre o objeto de discurso OWS e os referentes doações (que são anônimas, cuja distribuição é transparente)

${ }^{17}$ Uma das formas de coordenar as ações dos membros do Occupy foi a criação de um modelo descentralizado que funcionou através do Conselho de Porta-Vozes (Spokes Council), cujas reuniões eram mensais. 
e afiliação (que deve ser divulgada para os outros membros), que a transparência é inserida como valor positivo na cadeia equivalencial e, mais do que isso, norteia as práticas do movimento. Este é ainda retomado anaforicamente por meio da expressão definida (esse movimento), pronominalização (lo), e por anáfora direta correferencial em o Occupy Wall Street, separando o objeto do discurso do enunciador. No entanto, há a reaproximação em Solidarizamo-nos e [Nós] Somos Occupy Wall Street, com a inclusão dos dêiticos pessoais.

Diante do que fora dito, percebemos o quanto o processo de elaboração de referentes é um percurso não linear, podendo ser considerado rizomático. Como as escolhas linguísticas operadas são vistas como atendendo a um projeto de dizer, devem, por isso mesmo, ser consideradas construções políticas, produzindo efeitos, relacionados às interpretações diversas que fazemos em função dos pressupostos dos quais partimos, que não se deixam dominar pelo produtor, embora sejam, em algum grau, previsíveis. Trata-se do que Austin (1990, p. 89-90) chama dimensão perlocucionária da linguagem.

Desse modo, tomando como ponto de referência os dados construídos na análise, podemos afirmar um tipo de articulação que leva as diferenças a seu ponto de fusão. Não se trata de apagá-las, mas de deixá-las à sombra das equivalências, em nome da construção de uma identidade de grupo coesa com pretensões à universalidade. É dessa forma que o OWS opera, como um significante vazio, mantendo veladas as tensões inerentes à convivência das diferenças em uma organização política, ao articulá-las em torno de uma equivalência que termina por constituir a ideia de universalidade. O problema é que essa universalidade não escapa aos efeitos de uma ideologia neoliberal, configurando-se, apesar de peculiaridades importantíssimas, aos seus moldes.

A construção de equivalências, ao mesmo tempo que constitui uma ação política necessária e importante, apresenta também um aspecto problemático, em função dos modos como se dão a apropriação de significantes vazios na luta política. Embora, como argumenta o próprio Laclau, os significantes vazios sejam fundamentais ao processo democrático e à luta política, a sua mobilização contém sempre o risco de calar a voz de certas diferenças em favorecimento de outras, criando um efeito homogeneizante e sustentando o mito de um consenso que inexiste na prática. Assim, conforme afirma Hickel (2012), o OWS “ingenuamente ignora a realidade de partidarismo político e interesses de poder incompatíveis a favor de uma forma de inclusão que paralisa qualquer avanço sério”. 
Embora consideremos que, hoje, o movimento assumiu uma nova configuração, denominada por Kaminski (2014) de constelações políticas, o estudo dessa etapa inicial de constituição do Occupy tem sua importância para mostrar os riscos da construção de uma identidade política de resistência ao capitalismo dentro de um modo de produção cuja ideologia encontra-se profundamente enraizada no imaginário social. Também não se deve esquecer de que o poder é inerente à sociedade (MOUFFE, 2005), e que qualquer formação social, dada a própria pluralidade de interesses e valores, encontra obstáculos à promoção de um consenso e de uma coesão de grupo, e os grupos sociais precisam estar atentos a isso para não recair (sob outras facetas) no discurso de liberdade e igualdade nos moldes neoliberais.

Por fim, podemos nos perguntar se haveria outra forma de luta política e busca por emancipação social que poderia se esquivar a tal lógica. No entanto, quando recorremos ao próprio Laclau (2011), em sua discussão sobre a impossibilidade de subtração do poder e das diferenças nas relações sociais e nas práticas discursivas, percebemos que a emancipação social nos moldes de sua teoria do discurso deve ser vista não como um estágio social e político em que não haveria mais nada a ser superado, mas tão somente como a hegemonia de um estado de poder sobre outro cuja aferição deve ser feita em função das assimetrias, desigualdades e exclusões que produz.

\section{Conclusão}

No presente artigo, perseguimos o objetivo de analisar de que forma o movimento OWS, em seu discurso, construiu discursivamente uma cadeia de equivalências que culminou em uma formação identitária. Partimos da afirmação de que os objetos do mundo se constituem como objetos de discurso, à medida que a realidade é discursiva e intersubjetivamente construída. Vimos, baseados principalmente na teoria de Ernesto Laclau, como se dá a lógica de construção de identidades políticas, e sua busca para estabelecer certa fixidez e alcançar o status hegemônico na luta social, e como isso se dá via processos de referenciação, discussão que se mostrou bastante profícua na tarefa de fornecer um aparato de análise textual que nos permitisse transcender o próprio texto enquanto materialidade linguística e perceber sua relação profunda com o domínio sociodiscursivo. 
Esperamos, com isso, que este estudo possa contribuir para sublinhar o papel da linguagem no processo de construção e instauração de realidades. Assumindo posição central no trabalho de produção (da ilusão) de um mundo ontologicamente delimitado, cujo "mobiliário", para recuperar a expressão de Marcuschi (2007), aparenta por vezes guardar recalcitrante fixidez ${ }^{-}$embora, como vimos em Mondada e Dubois (2003), suas categorias encontrem-se em permanente estado de instabilidade generalizada ${ }^{-}$, a linguagem tanto comporta senhas de opressão e estigmatização, quanto, de outro modo, tem o potencial para tornar-se lugar de resistência, subversão e mudança social.

Esse aspecto dos processos discursivos nos exorta, por isso mesmo, a um permanente estado de vigília em relação às práticas de linguagem, colocando-nos no lugar sempre arriscado da expectativa de crítica, para dimensionarmos não apenas "o ser" por ela ontificado, mas "um vir-a-ser" pragmaticamente investido que lhe desenhe novas potências, novos modos de estar no mundo para nós, que estamos, irremediavelmente, na linguagem. E deve ser, conforme tentamos mostrar neste artigo, uma das tarefas seminais de todos os movimentos inscritos no campo do fazer político.

\section{Referências}

APOTHÉLOZ, D.; REICHLER-BÉGUELIN, M.-J. Construction de la référence et strategies de designation. Tradução (inédita) Mônica Magalhães Cavalcante. In: BERRENDONNER, A.; REICHLER-BÉGUELIN, M.-J. (Org.). Du sintagme nominal aux objects-de-discours. Neuchâtsh: Université de Neuchâtsh, 1995. p. 227-271.

AUSTIN, J. L. Quando dizeré é fazer. Palavras e ação. Porto Alegre: Artes Médicas, 1990.

BEAUGRANDE, R.-A. de. New foundations for a science of text and discourse: cognition, communication and the freedom of access to knowledge and society. New Jersey: Ablex Publishing Corporation, 1997.

CASTELLS, M. Redes de indignação e esperança: movimentos sociais na era da internet. Rio de Janeiro: Zahar, 2013. 
CIULLA E SILVA, A. Os processos de referência e suas funções discursivas: o universo literário dos contos. 2008. Tese (Doutorado em Linguística) Universidade Federal do Ceará, Fortaleza.

CUSTÓDIO FILHO, V. Múltiplos fatores, distintas interações: esmiuçando o caráter heterogêneo da referenciação. 2011. Tese (Doutorado em Linguística) - Universidade Federal do Ceará, Fortaleza.

HALLIDAY, M. A. K. An introduction to functional grammar. $2^{\text {nd }}$ ed. London: Edward Arnold, 1994.

HANKS, W. F. O que é contexto. In: BENTES, A. C.; REZENDE, R. C.; MACHADO, M. A. R. (Org.). Lingua como prática social: das relações entre língua, cultura e sociedade a partir de Bourdieu e Bakhtin. São Paulo: Cortez, 2008. p. 118-168.

HICKEL, J. Liberalism and the politics of Occupy Wall Street. Anthropology of this Century, 4., 2012. Disponível em: <http://bit.do/cU4An>. Acesso em: 13 fev. 2014.

KAMINSKI, R. Indignados no cenário da crise: movimentos sociais antissistêmicos no século XXI e a emergência da cultura política em rede. 2014. Dissertação (Mestrado em Ciências Sociais) - Universidade Federal do Ceará, Fortaleza.

KOCH, I. V. Referenciação e orientação argumentativa. In: KOCH, I. G. V.; MORATO, E. M.; BENTES, A. C. (Org.) Referenciação e discurso. São Paulo: Contexto, 2005. p. 33-52.

$\mathrm{KOCH}, \mathrm{I}$. V. Referenciação. In: KOCH, I. V. Introdução à linguística textual: trajetória e grandes temas. São Paulo: Contexto, 2015. p. 59-83.

LACLAU, E. New reflections on the revolution of our time. London: Verso, 1990.

LACLAU, E. Emancipação e diferença. Rio de Janeiro: EDUERJ, 2011.

LACLAU, E.; MOUFFE, C. Hegemony and socialist strategy: Towards a radical democratic politics. London: Verso, 2001. 
MARCUSCHI, L. A. Anáfora indireta: o barco textual e suas âncoras. In: KOCH, I. G. V.; MORATO, E. M.; BENTES, A. C. (Org.) Referenciação e discurso. São Paulo: Contexto, 2005. p. 53-101.

MARCUSCHI, L. A construção do mobiliário do mundo e da mente: linguagem, cultura e categorização. In: MARCUSCHI, L. A. Cognição, linguagem e práticas interacionais. Rio de Janeiro: Lucerna, 2007. p. 124-145. (Série Dispersos).

MATURANA, H. Cognição, ciência e vida cotidiana. Tradução e organização Cristina Magro e Victor Paredes. Belo Horizonte: Ed. UFMG, 2001. MENDONCA, D. de. Como olhar "o político" a partir da teoria do discurso. Revista Brasileira de Ciência Política, Brasília, n. 1, p. 153-159, jan./jun. 2009.

MENDONÇA, D. de. Antagonismo como identificação política. Revista Brasilera de Ciência Política, n. 9. Brasília, p. 205-228, set./dez. 2012.

MONDADA, L.; DUBOIS, D. Construção dos objetos de discurso e categorização: uma abordagem dos processos de referenciação. Tradução Mônica Magalhães Cavalcante. In: CAVALCANTE, M. M.; BIASIRODRIGUES, B.; CIULLA E SILVA, A. (Org.). Referenciação. São Paulo: Contexto, 2003. p. 17-52.

MOUFFE, C. On the political. London; New York: Routledge, 2005.

VAN DIJK, T. A. Discurso e poder. São Paulo: Contexto, 2008.

Recebido em: 30/05/2015

Aceito: 18/10/2015 